\title{
A randomized, double-blind, placebo-controlled trial of simvastatin to treat Alzheimer disease
}
M. Sano, PhD
K.L. Bell, MD
D. Galasko, MD
J.E. Galvin, MD, MPH
R.G. Thomas, PhD
C.H. van Dyck, MD
P.S. Aisen, MD

Address correspondence and reprint requests to Dr. Mary Sano, Mount Sinai School of Medicine and the James J. Peters VAMC, 130 W. Kingsbridge Rd., Code 150 Rm 1F01, Bronx, NY 10468

mary.sano@mssm.edu

\section{ABSTRACT}

Background: Lowering cholesterol is associated with reduced CNS amyloid deposition and increased dietary cholesterol increases amyloid accumulation in animal studies. Epidemiologic data suggest that use of 3-hydroxy-3-methylglutaryl coenzyme A (HMG-CoA) reductase inhibitors (statins) may decrease the risk of Alzheimer disease (AD) and a single-site trial suggested possible benefit in cognition with statin treatment in $A D$, supporting the hypothesis that statin therapy is useful in the treatment of $A D$.

Objective: To determine if the lipid-lowering agent simvastatin slows the progression of symptoms in AD.

Methods: This randomized, double-blind, placebo-controlled trial of simvastatin was conducted in individuals with mild to moderate $A D$ and normal lipid levels. Participants were randomly assigned to receive simvastatin, $20 \mathrm{mg} /$ day, for 6 weeks then $40 \mathrm{mg}$ per day for the remainder of 18 months or identical placebo. The primary outcome was the rate of change in the Alzheimer's Disease Assessment Scale-cognitive portion (ADAS-Cog). Secondary outcomes measured clinical global change, cognition, function, and behavior.

Results: A total of 406 individuals were randomized: 204 to simvastatin and 202 to placebo. Simvastatin lowered lipid levels but had no effect on change in ADAS-Cog score or the secondary outcome measures. There was no evidence of increased adverse events with simvastatin treatment.

Conclusion: Simvastatin had no benefit on the progression of symptoms in individuals with mild to moderate AD despite significant lowering of cholesterol.

Classification of evidence: This study provides Class I evidence that simvastatin $40 \mathrm{mg} /$ day does not slow decline on the ADAS-Cog. Neurology ${ }^{\circledR} 2011 ; 77: 556-563$

\section{GLOSSARY}

$\mathbf{A} \boldsymbol{\beta}=$ amyloid $\beta$ peptide; $\mathbf{A C h E}=$ acetylcholinesterase; $\mathbf{A D}=$ Alzheimer disease; $\mathbf{A D A S}-$ Cog $=$ Alzheimer's Disease Assessment Scale-cognitive portion; ADCS = Alzheimer's Disease Cooperative Study; ADCS-ADL = Alzheimer's Disease Cooperative Study Activities of Daily Living; ADCS-CGIC = Alzheimer's Disease Cooperative Study Clinical Global Impression of Change; ADCS-RUI = Alzheimer's Disease Cooperative Study Resource Use Instrument; ALT = alanine aminotransferase; AST = aspartate aminotransferase; $\mathbf{A T P}=$ Adult Treatment Panel; $\mathbf{C R P}=$ C-reactive protein; $\mathbf{G E E}=$ generalized estimating equation; HDL = high-density lipoprotein; HMG-CoA = 3-hydroxy-3-methylglutaryl coenzyme A; ITT = intent-to-treat; LDL = low-density lipoprotein; MMSE = Mini-Mental State Examination; NPI = Neuropsychiatric Inventory; QOL = quality of life.

Substantial evidence from laboratory research in animal model and cell culture systems, ${ }^{1}$ some ${ }^{2-5}$ but not all ${ }^{6}$ observational epidemiologic studies, and some small clinical trials ${ }^{7,8}$ suggest that lowering cholesterol may favorably influence the pathology of Alzheimer disease (AD) and thereby slow the clinical progression.

The gene for apoE, a cholesterol transporter, is an important determinant of risk of sporadic $\mathrm{AD}^{9}$ and cholesterol may be involved in the accumulation of amyloid in the brain. Animal studies have demonstrated that a high-cholesterol diet can increase levels of the amyloid $\beta$ peptide $(\mathrm{A} \beta)$, the primary constituent of amyloid plaques, ${ }^{10,11}$ and conversely, statins may

From the Mount Sinai School of Medicine (M.S.), New York; the James J. Peters VAMC (M.S.), Bronx; Department of Neurology (K.L.B.)

Columbia University Medical Center, New York, NY; Department of Neurosciences (D.G., P.S.A.), University of California, San Diego; Center of

Excellence on Brain Aging and Alzheimer Disease Center (J.E.G.), New York University Langone Medical Center, New York; Department of Family and Preventive Medicine (R.G.T.), University of California, San Diego, La Jolla; and Alzheimer's Disease Research Unit (C.H.v.D.), Yale University School of Medicine, New Haven, CT.

Study funding: Funding information is provided at the end of the article.

Disclosure: Author disclosures are provided at the end of the article. 
reduce $A \beta$ levels in these animal models. ${ }^{12}$ Additionally, neurofibrillary tangles may be reduced by statins. ${ }^{13}$

C-reactive protein (CRP), a plasma inflammatory marker, elevated in association with cardiovascular risks, and in the presence of dementia, including $\mathrm{AD},{ }^{14}$ is lowered by statins. ${ }^{15,16}$ Taken together, these studies suggest that cholesterol may influence $A D$ via multiple pathways.

Simvastatin, a 3-hydroxy-3-methylglutaryl coenzyme A (HMG-CoA) reductase inhibitor, penetrates the CNS and has been shown to reduce the risk of cardiovascular disease and death. It was selected for use in this randomized clinical trial to test the hypothesis that lipid lowering could reduce the clinical progression in subjects with $\mathrm{AD}$ who have cholesterol levels not otherwise requiring treatment.

METHODS Study design. The primary study objective was to determine if simvastatin slows the progression of symptoms in AD. It was designed to provide Class I evidence that treatment with simvastatin would slow the decline on the cognitive portion of the Alzheimer's Disease Assessment Scale (ADAS).

The trial was conducted by the Alzheimer's Disease Cooperative Study (ADCS), a consortium of US centers funded by the National Institute on Aging. It used a placebo-controlled, parallel design study with 2 groups.

Standard protocol approvals, registration, and patient consent. Forty-five sites participated in this trial after obtaining approval from their local Institutional Review Boards. Informed consent was obtained from subjects or legally authorized representatives, according to local guidelines. Of note, 13 sites participated in a substudy to examine the views of patients with $\mathrm{AD}$ and their study partners on the ethics of proxy consent for clinical research ${ }^{17}$ and to assess the ability of a standardized capacity assessment procedure to identify persons who are capable of giving their own informed consent. ${ }^{18}$ The trial was registered as follows: clinicaltrials.gov Identifier: NCT00053599.

Subjects. Individuals with probable $\mathrm{AD},{ }^{19}$ recruited from local clinic populations and via locally approved advertisements, were eligible if they were medically stable. Inclusion criteria included age older than 50 years and a Mini-Mental State Examination $(\mathrm{MMSE})^{20}$ score within the range of 12 to 26 . Individuals were excluded if they had other neurologic or psychiatric diagnosis that could interfere with cognitive function. They were also excluded if they were taking lipid-lowering drugs, or if they had conditions requiring cholesterol lowering treatment as defined by the Adult Treatment Panel (ATP III) guidelines ${ }^{21}$ which were current during the period of study. They were also excluded if they had low-density lipoprotein (LDL) cholesterol below 80 $\mathrm{mg} / \mathrm{dL}$ or triglycerides $>500 \mathrm{mg} / \mathrm{dL}$. Individuals were also excluded if they had recently taken drugs with significant central anticholinergic effects, sedatives, antiparkinsonian medications, or any investigational treatment for $\mathrm{AD}$. Other excluded medications were those that are specifically contraindicated with simva- statin as well as those that could interact with CYP $3 \mathrm{~A} 4$ to either increase or decrease the level of simvastatin. Stable use (for at least 3 months) of cholinesterase inhibitors and memantine was allowed.

Randomization and masking. The randomization sequence was generated with equal probability of assignment to drug and placebo using a random permuted block treatment assignment, stratified by site. The randomization sequence was generated by the ADCS data center. "Scratch-off" codebreakers were used so that instances of unblinding would be documented; all codebreakers were collected at the end of the trial. Adequacy of the blind was assessed by questionnaires completed by participants, caregivers, psychometrists, and site investigators.

Study medication. The dose of simvastatin was based on known lipid-lowering capacity in those with hypercholesterolemia. The initiation dose of $20 \mathrm{mg}$ per day on average reduces total cholesterol by $28 \%$, LDL cholesterol by $34 \%$, and increases high-density lipoprotein (HDL) by $8 \%$. The dose of $40 \mathrm{mg}$ per day, which was used after the first 6 weeks, typically reduces total cholesterol by $25 \%$ to $31 \%$, LDL cholesterol by $41 \%$, and increases HDL by $9 \%$ to $13 \%$ in patients with hypercholesterolemia. Study medication administration used this single dose escalation with all subjects receiving one tablet per day in the evening. For the first 6 weeks, each contained active drug (simvastatin $20 \mathrm{mg}$ ) or identical placebo. The dose was increased to $40 \mathrm{mg}$ of simvastatin for the active drug or identical placebo for the remainder of the 18-month study. Study medication was packaged and dispensed in 6-week supplies for 2 intervals followed by a 3-month supply and 2 6-month supplies, and was dispensed at each visit.

Outcome measures. The primary outcome measure was the rate of change on the cognitive portion of the ADAS (ADAS$\mathrm{Cog}$ ) score, ${ }^{22}$ a psychometric instrument that evaluates memory, attention, reasoning, language, orientation, and praxis. The score ranges from 0 to 70 and a higher score indicates more impairment. A positive change score indicates cognitive worsening.

Secondary outcome measures included the ADCS Clinical Global Impression of Change (ADCS-CGIC), ${ }^{23}$ the MMSE, the Dependence Scale, ${ }^{24}$ the ADCS Activities of Daily Living (ADCS-ADL), Neuropsychiatric Inventory (NPI), ${ }^{25}$ and 3 supplemental cognitive tests from the ADCS instrument protocol, including Maze A2, a measure of executive function; Number Cancellation, a measure of visual attention; and Delayed Word Recall. ${ }^{26}$ Quality of life (QOL) was measured with is a 13-item scale which ranges from 0 to 52 , with a higher score indicative of a better QOL. ${ }^{27}$ QOL is rated by both the subject and the informant. The ADCS Resource Use Instrument (ADCS-RUI) was used to measure the number of hours per day of assistance from primary and secondary caregivers. ${ }^{28}$ Raters for all outcomes were trained at an investigator meeting and certified through online assessments and remained constant throughout the trial whenever possible. Primary and secondary outcomes were measured at 3, 6, 12, and 18 months after baseline.

Safety measures included standard reporting of any adverse events, laboratory abnormality, or endorsement of items from a "symptom checklist" which directly inquired about known side effects of the drug with specific queries for muscle pain, tenderness, or weakness.

Laboratory evaluations. APOE genotyping was carried out on all subjects who consented to be used as a predictor of clinical change over time. Routine laboratory studies included lipids levels (which were blind to the investigative staff) and liver function 
tests at follow-up visits. CRP was collected at baseline and at 18 months. Special attention was given to serum transaminases and aspartate aminotransferase (AST) or alanine aminotransferase (ALT) elevations greater than or equal to 3 times the upper limit of normal, which required discontinuation of study drug.

Statistical analysis. The primary analysis used the generalized estimating equations (GEE) method to assess group differences (simvastatin vs placebo) in rate of change on the ADAS-Cog score. The power calculations were based on GEE analysis of repeated ADAS-Cog score data from a previous trial with similar subjects which identified visit-to-visit correlation, of 0.853 , an ADAS-Cog score SD of 11.5, and an annual change among the placebo of 6.3 points. With a dropout rate estimated at $30 \%, \alpha$ set at 0.05 , and a sample of 400 , there was $80 \%$ power to see a $20 \%$ difference in drug vs placebo rate of change.

The primary analysis was an intent-to-treat (ITT) analysis. All available ADAS-Cog assessments were used in the analysis for subjects who discontinued medication but agreed to be followed. A list of covariates anticipated to be associated with rate of change in ADAS-Cog over 18 months included APOE $\varepsilon 4$ allele count, baseline lipid level, demographic variables (age, education, gender, race/ethnicity), and clinical variables (i.e., duration of disease, baseline measures of ADAS-Cog, ADCS-ADL, and NPI). A data analysis plan, finalized prior to breaking the blind, added the MMSE to the covariates described above. These variables were to be included as covariates in secondary analyses of the primary outcome using the GEE analysis model only if found to be moderately associated both with treatment group $(p<0.1)$ and with response $(p<0.15)$. In addition to the ITT analysis, both a completers (those who completed the protocol) and compliers (those who ingested $\geq 80 \%$ of the prescribed medication based on return pill count) analyses were conducted. Further, as a confirmatory analysis, and to allow comparison with other rate of change AD trials, a set (ITT, completers, compliers) of change score analyses were performed with 18 -month values imputed using the multiple imputation method..$^{29}$

The statistical software for the primary hypothesis analysis was $R$ (version 2.6.2, 2/8/2008). ${ }^{30}$

RESULTS Study participants and follow-up. The flow of participants though the study is summarized in figure 1. Recruitment continued from December 11,2002 , to January 11,2006 , and study completion (last subject assessed) was September 19, 2007. A total of 685 participants were screened and 406 met criteria and were randomized with 204 in the simvastatin group and 202 in the placebo group.
Discontinuation rates in the active treatment group and placebo group were similar (40/202 in the placebo arm vs 43/204 in treatment arm; $p=0.766$ ). Predominant reasons for early discontinuation were side effect (16 in placebo arm vs 13 in treatment arm) and study partner's unwillingness or inability to continue (7 in the placebo arm vs 22 in the treatment arm). The median length of follow-up was 17.9 months and this was comparable between arms. There were no statistically significant differences in baseline characteristics between participants who discontinued early and study completers (data available by request from authors).

Table 1 lists the baseline demographic and clinical features and other covariates. The placebo group had significantly more Hispanics $(p=0.012)$ and slightly higher ADCS-ADL scores $(p=0.041)$ than the simvastatin group. Differences in the MMSE and LDL levels between the 2 groups also met criteria $(p<0.10)$ for consideration for inclusion in the GEE model depending on their relationship to the outcome.

There was no difference in the use of approved antidementia medications during the study. A total of $94.3 \%$ of participants were taking a cholinesterase inhibitor (placebo arm: 94.06; treatment arm: 96.61\%). Memantine was taken by $54.19 \%$ (placebo arm: 53.96\%; treatment arm: 54.41\%). Both agents were used by $51.72 \%$ of the cohort (placebo arm: 50.5\%; treatment arm: 52.94\%). Compliance was comparable between groups $(90.54 \%$ in the placebo group and $91.67 \%$ in the treatment group; $p=0.841$ ).

Total cholesterol and LDL levels were significantly reduced by the treatment compared to placebo $(p<0.001)$; the reduction was $23 \%$ in total cholesterol and $37 \%$ in LDL. HDL levels were also increased with treatment by $2 \%(p=0.02)$.

Primary outcome. Ethnicity and baseline MMSE, ADCS-ADL, and LDL levels met criteria for consideration as confounders in outcome analyses. Presence

Figure 1 Flow of participants

Subjects screened, $n=685$

Subjects randomized, $\mathrm{n}=406$

Subjects not randomized, $\mathrm{n}=279$

Treatment group, $\mathrm{n}=\mathbf{2 0 4} \mathbf{( 4 9 . 7 5 \% )}$

Lost to follow-up before month $18, n=15$

Completed month 18 on medication, $n=145$

Completed month 18 of medication, $n=3$
Placebo group, $\mathbf{n = 2 0 2} \mathbf{( 5 0 . 2 5 \% )}$

Lost to follow-up before month $18, n=10$

Completed month 18 on medication, $n=152$

Completed month 18 of medication, $n=4$ 


\begin{tabular}{|c|c|c|c|c|}
\hline \multicolumn{5}{|c|}{ Table 1 Baseline characteristics of the subjects } \\
\hline Variable & $\begin{array}{l}\text { Placebo } \\
\text { group }(n=202)\end{array}$ & $\begin{array}{l}\text { Simvastatin } \\
\text { group }(n=204)\end{array}$ & $\begin{array}{l}\text { All subjects } \\
(\mathrm{n}=\mathbf{4 0 6 )}\end{array}$ & $\begin{array}{l}\text { Placebo/simvastatin } \\
\text { difference } p \text { value }\end{array}$ \\
\hline Age, $y$, mean $\pm S D$ & $75.1 \pm 9.0$ & $74.0 \pm 9.6$ & $74.6 \pm 9.3$ & 0.2931 \\
\hline Female sex, $n(\%)$ & $121(59.9)$ & $120(58.8)$ & $241(59.4)$ & 0.8404 \\
\hline Education, $y$, mean $\pm S D$ & $14.2 \pm 3.3$ & $14.3 \pm 3.2$ & $14.3 \pm 3.2$ & 0.9273 \\
\hline Duration of disease, $y$ & $4.23(2.63)$ & $4.03(2.58)$ & $4.13(2.61)$ & 0.3922 \\
\hline Caucasian, $\mathrm{n}(\%)$ & $188(93.1)$ & $181(88.7)$ & 369 (90.9) & 0.1672 \\
\hline Hispanic/Latino, n (\%) & $18(9.0)$ & $6(3.0)$ & $24(6.0)$ & 0.0188 \\
\hline APOE $\epsilon 4$ carrier, $n$ (\%) & $100(55.3)$ & $108(61.0)$ & $208(58.1)$ & 0.2853 \\
\hline Total cholesterol, mean \pm SD & $208.8 \pm 28.6$ & $215.0 \pm 32.5$ & $211.9 \pm 30.8$ & 0.1153 \\
\hline Low-density lipoprotein & $123.2 \pm 24.4$ & $128.9 \pm 26.4$ & $126.0 \pm 25.1$ & 0.0529 \\
\hline High-density lipoprotein & $61.1 \pm 16.7$ & $60.7 \pm 16.2$ & $60.9 \pm 16.4$ & 0.6945 \\
\hline ADAS-Cog score, mean \pm SD & $23.9 \pm 10.5$ & $24.5 \pm 9.7$ & $24.2 \pm 10.1$ & 0.2647 \\
\hline MMSE score, mean \pm SD & $20.7 \pm 4.9$ & $20.0 \pm 4.5$ & $20.4 \pm 4.7$ & 0.0895 \\
\hline$A D C S-A D L$, mean $\pm S D$ & $68.6 \pm 10.4$ & $67.2 \pm 10.0$ & $67.9 \pm 10.2$ & 0.0414 \\
\hline Dependence scale, mean \pm SD & $4.9 \pm 2.3$ & $5.2 \pm 2.3$ & $5.1 \pm 2.3$ & 0.2432 \\
\hline Neuropsychiatric Inventory, mean \pm SD & $7.8 \pm 8.3$ & $9.2 \pm 10.5$ & $8.5 \pm 9.5$ & 0.6246 \\
\hline
\end{tabular}

Abbreviations: ADAS-Cog = Alzheimer's Disease Assessment Scale-cognitive portion; ADCS-ADL = Alzheimer's Disease Cooperative Study Activities of Daily Living; MMSE = Mini-Mental State Examination.

of the APOE4 allele was not different in the 2 groups and not associated with the rate of change in the ADAS-Cog score and therefore not included in the analysis. The effect of treatment on the primary outcome measure is shown in figure 2 and table 2 . In the primary GEE analysis the rate of change in ADAS-
Cog score did not differ between treatment groups $(p=0.25 ; 95 \% \mathrm{CI}-0.0462$ to 0.1680$)$. The annual point change was 5.52 points for the placebo group and 6.28 points for the treatment group. Further, using a median split we examined those of low and high age and low and high baseline MMSE score and

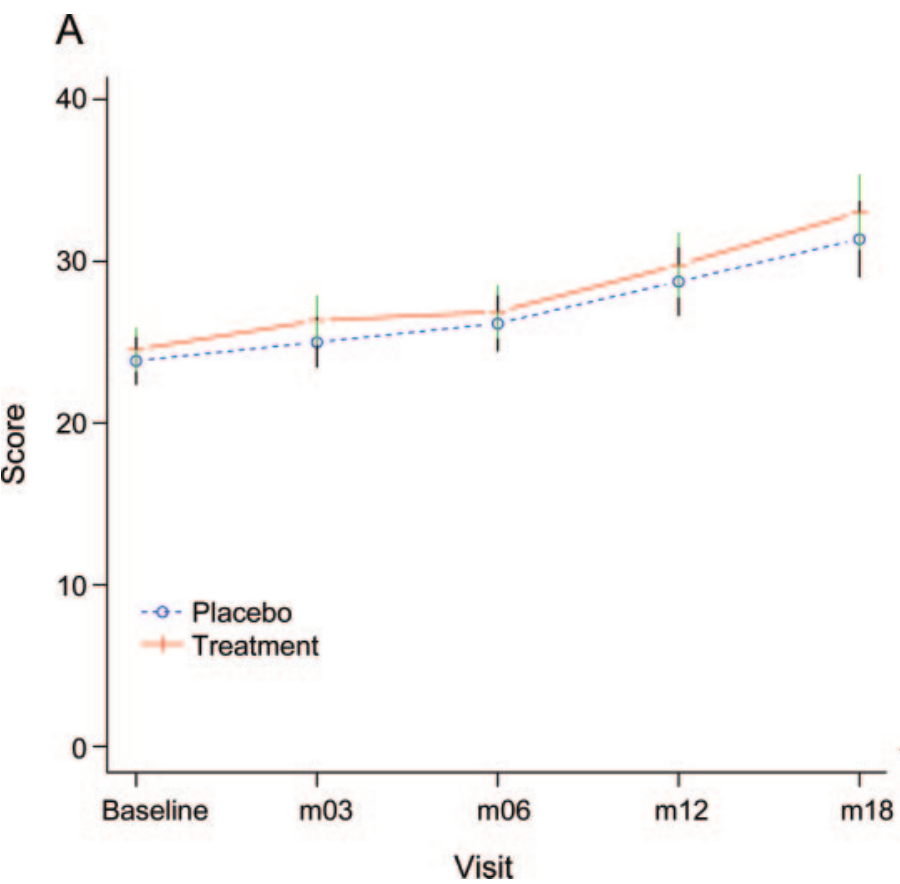

B

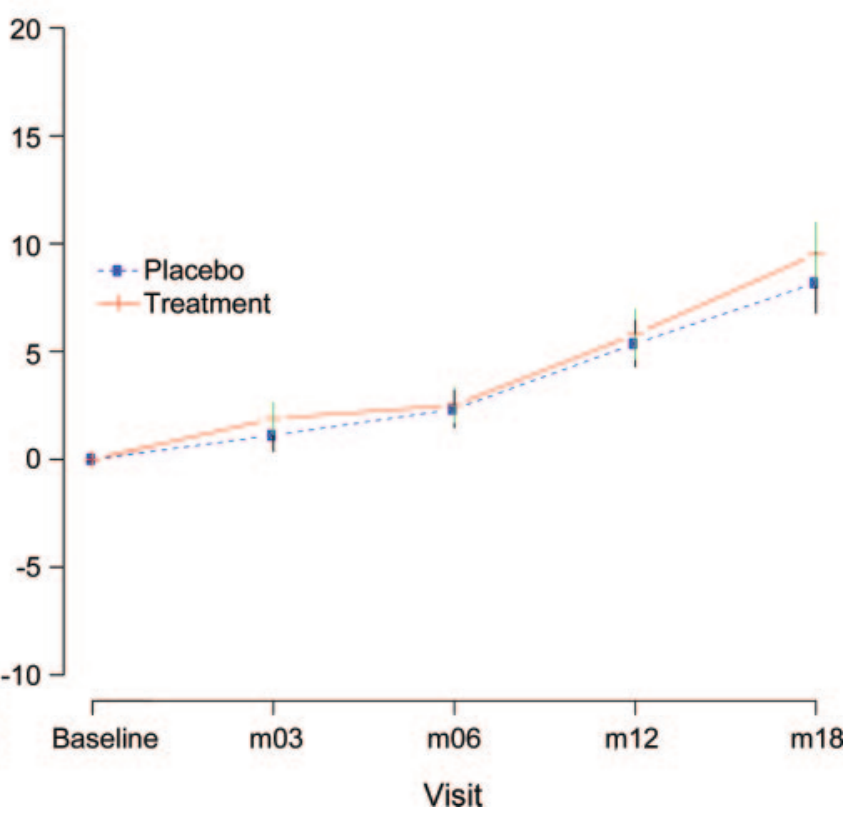

Mean of ADAS-Cog = Alzheimer's Disease Assessment Scale-cognitive portion total score (A) and change score (B) by treatment and visit. Presented with $95 \%$ confidence intervals. 


\begin{tabular}{|c|c|c|c|c|}
\hline \multicolumn{5}{|c|}{ Changes from baseline in cognitive and functional measures } \\
\hline \multirow{2}{*}{$\begin{array}{l}\text { Test and cognitive and } \\
\text { functional measures }\end{array}$} & \multicolumn{4}{|c|}{ Change in score from baseline } \\
\hline & $3 \mathrm{mo}$ & $6 \mathrm{mo}$ & $12 \mathrm{mo}$ & $18 \mathrm{mo}$ \\
\hline \multicolumn{5}{|l|}{ ADAS-Cog } \\
\hline Placebo & $1.11 \pm 5.32$ & $2.32 \pm 5.90$ & $5.36 \pm 6.95$ & $8.18 \pm 8.70$ \\
\hline Simvastatin & $1.89 \pm 5.35$ & $2.51 \pm 5.61$ & $5.79 \pm 7.76$ & $9.51 \pm 9.48$ \\
\hline \multicolumn{5}{|l|}{ MMSE } \\
\hline Placebo & $-0.10 \pm 3.10$ & $-0.89 \pm 3.23$ & $-2.28 \pm 4.08$ & $-3.75 \pm 4.38$ \\
\hline Simvastatin & $-0.52 \pm 2.74$ & $-0.72 \pm 3.26$ & $-2.47 \pm 3.80$ & $-4.23 \pm 4.77$ \\
\hline \multicolumn{5}{|l|}{ Dependence scale } \\
\hline Placebo & $-0.15 \pm 0.87$ & $-0.21 \pm 0.83$ & $-0.36 \pm 0.96$ & $-0.53 \pm 1.10$ \\
\hline Simvastatin & $-0.04 \pm 0.85$ & $-0.10 \pm 1.04$ & $-0.26 \pm 1.02$ & $-0.48 \pm 1.09$ \\
\hline \multicolumn{5}{|c|}{ Activities of daily living scale } \\
\hline Placebo & $-1.20 \pm 6.09$ & $-3.95 \pm 8.42$ & $-6.21 \pm 10.94$ & $-9.62 \pm 13.86$ \\
\hline Simvastatin & $-1.54 \pm 7.44$ & $-3.66 \pm 8.18$ & $-7.45 \pm 10.18$ & $-10.47 \pm 13.37$ \\
\hline \multicolumn{5}{|c|}{ Neuropsychiatric Inventory } \\
\hline Placebo & $0.21 \pm 8.02$ & $1.26 \pm 9.16$ & $3.60 \pm 10.38$ & $3.78 \pm 10.73$ \\
\hline Simvastatin & $-0.64 \pm 8.61$ & $-0.09 \pm 9.61$ & $1.95 \pm 10.64$ & $3.21 \pm 12.71$ \\
\hline
\end{tabular}

Abbreviations: ADAS-Cog = Alzheimer's Disease Assessment Scale-cognitive portion; MMSE = Mini-Mental State Examination.

found no difference in rate of ADAS-Cog change between the simvastatin vs placebo groups in any of the subgroups.

Secondary outcomes. There were no significant differences between groups in the secondary outcomes (MMSE, Dependence Scale, ADCS-ADL, and NPI or the additional cognitive measures) (table 2) or the CGIC (data available upon request). There were no significant differences between groups in QOL as measured by informant or subject. Caregiving hours at baseline were comparable between groups (placebo: $2.03 \pm 4.1$ vs treatment: $2.44 \pm 5.0$ ) and did not change throughout the trial.

CRP. At baseline, CRP values were equivalent between groups. There was a significant reduction in CRP in the treatment group compared to the placebo group $(-0.017 \pm 1.56$ in the placebo group vs $-0.031 \pm 0.77$ in the treatment group; $p<$ $0.005)$.

Effects of antidementia drug use. Cholinesterase inhibitor medication (acetylcholinesterase $[\mathrm{AChE}]$ ) exposure was reported at some point during the trial in 383/406 (94\%) and 220 (54\%) reported use of memantine at some point during the trial, respectively. Of those exposed to memantine, 210 (95\%) were also exposed to AChE, resulting in $210(52 \%)$ with reported exposure to both drugs. There were no differences in rate of exposure by treatment arm. The use of antidementia drugs alone or in combination did not change the primary results. That is, even in the presence of anti- dementia drugs, there was no benefit in the rate of decline on the ADAS-Cog in the simvastatin group compared to the placebo groups.

Blindness evaluation. There was no difference in perceived assignment in the treatment vs placebo group for participants, informants, study coordinators, and study physicians.

Safety data. The number of subjects with one or more adverse events in the placebo group, 181/202 (89.6\%), and treatment group, 189/204 (92.7\%), did not differ ( $p=0.30$ ). Similarly, the groups did not differ in the number of subjects with serious adverse events (placebo group: 54/202 [26.7\%]; treatment group: 56/204 [27.5\%]; $p=0.91$ ), the number of subjects with serious adverse events requiring hospitalization (placebo group: 46/202 [22.7\%], active treatment group: $53 /$ 204 [25.9\%]; $p=0.52$ ), and the number of deaths (placebo group: 9/202 [4.5\%], active group: 5/204 [2.5\%]; $p=0.0 .29)$.

Liver enzyme elevations (defined as 3 times the upper limit of normal for $\gamma$-glutamyl transpeptidase, ALT, or AST) were noted in $2 \%$ of treatment and $4 \%$ placebo group. There were no elevations in creatine phosphokinase.

Treatment-emergent adverse events were grouped into categories for analysis. The most commonly occurring adverse events were falls, agitation, and anxiety. However, there was no significant difference between drug and placebo in any category. Those events that occurred in at least $5 \%$ of either group are reported in table 3 . 


\begin{tabular}{|c|c|c|}
\hline \multirow{2}{*}{$\begin{array}{l}\text { Table } 3 \\
\text { Symptom }\end{array}$} & \multicolumn{2}{|c|}{$\begin{array}{l}\text { No. }(\%) \text { of individuals in each group } \\
\text { experiencing an adverse event }{ }^{\mathrm{a}}\end{array}$} \\
\hline & $\begin{array}{l}\text { Placebo } \\
\text { group }(n=202)\end{array}$ & $\begin{array}{l}\text { Treatment } \\
\text { group }(n=204)\end{array}$ \\
\hline $\begin{array}{l}\text { Abdominal } \\
\text { discomfort }\end{array}$ & $11(5.4)$ & $13(6.4)$ \\
\hline Nausea & $11(5.4)$ & 23 (11.3) \\
\hline Diarrhea & 28 (13.9) & 40 (19.6) \\
\hline Asthenia & 43 (21.3) & 43 (21.1) \\
\hline $\begin{array}{l}\text { Urinary tract } \\
\text { infection }\end{array}$ & $12(5.9)$ & $14(6.9)$ \\
\hline Fall & 63 (31.2) & 57 (27.9) \\
\hline Arthralgia & 24 (11.9) & 25 (12.2) \\
\hline Myalgia & $10(4.9)$ & $11(5.4)$ \\
\hline Back pain & $19(9.4)$ & 21 (10.3) \\
\hline $\begin{array}{l}\text { Joint } \\
\text { swelling }\end{array}$ & $10(4.9)$ & $13(6.4)$ \\
\hline Headache & $13(6.4)$ & $19(9.3)$ \\
\hline Dizziness & $29(14.4)$ & $18(8.8)$ \\
\hline Anxiety & 34 (16.8) & 48 (23.5) \\
\hline Restlessness & $12(5.9)$ & 24 (11.8) \\
\hline Agitation & 47 (23.3) & $50(24.5)$ \\
\hline Depression & $11(5.4)$ & $14(6.9)$ \\
\hline Somnolence & 29 (14.4) & 34 (16.7) \\
\hline $\begin{array}{l}\text { Depressed } \\
\text { mood }\end{array}$ & 28 (13.9) & 31 (15.2) \\
\hline Insomnia & $18(8.9)$ & $19(9.3)$ \\
\hline Crying & 26 (12.9) & $26(12.7)$ \\
\hline Pollakiuria & $21(10.4)$ & 29 (14.2) \\
\hline Cough & 24 (11.9) & 26 (12.7) \\
\hline Dyspnea & $15(7.4)$ & $6(2.9)$ \\
\hline Rash & $15(7.4)$ & $19(9.3)$ \\
\hline
\end{tabular}

a Events reported for those symptoms occurring in 5\% of either group.

DISCUSSION Simvastatin treatment for 18 months had no effect on the progression of symptoms in individuals with mild to moderate $\mathrm{AD}$. No drug-placebo differences were observed on the change in ADAS-Cog score or on the secondary outcome measures. Although this study examined individuals with normal lipid levels (i.e., levels that do not require lipid-lowering therapy to prevent cardiovascular disease), the treatment regimen significantly reduced both total cholesterol and LDL levels, marginally raised HDL levels, and reduced CRP. Of note was the relatively benign side effect profile of simvastatin in this frail elderly population. There were no treatment differences in liver enzyme elevations, reports of muscle pain, complaints of change in consciousness, or confusion.

Despite the fact that simvastatin penetrates the CNS, the results are consistent with those for the nonpenetrating atorvastatin, which was assessed in a trial of comparable design. ${ }^{31}$ It remains unknown whether statin therapy has a favorable impact on individuals with $\mathrm{AD}$ and elevated cholesterol levels; such individuals should receive lipid-lowering therapy for cardiovascular health, so a placebo-controlled statin trial may be unethical. However, such a benefit would seem unlikely, given the results of 2 large randomized clinical trials of primary prevention of cardiovascular outcomes among individuals without $\mathrm{AD}$ and elevated cholesterol levels. ${ }^{32,33}$ These trials assessed cognition and incident dementia as secondary measures and found no benefit of statin use, despite significant benefit on cardiovascular outcomes. Also unaddressed by the present study is the utility of statin therapy in individuals who do not otherwise require lipid lowering, at predementia stages, mild cognitive impairment, or presymptomatic $\mathrm{AD}$.

Recent reports have suggested that the use of antidementia drugs may reduce the sensitivity of outcome measures such as the ADAS-Cog and the CGIC to capture treatment effects. ${ }^{34}$ However, this and other trials have demonstrated that these outcomes are reasonably efficient in measuring change in clinical trials of 18 months-even in the presence of stable doses of antidementia drugs. ${ }^{35,36}$ Also, some have reported an enhancement of benefit in those using cholinesterase inhibitors and statins in post hoc analysis. ${ }^{37}$ We found no evidence of enhancement of benefit in the combined use of statins and cholinesterase inhibitors. These results suggest that permitting background use of standard medications does not affect the ability to observe decline in trials of this length.

Mechanistically, it remains unclear whether the regimen of simvastatin used in this trial influenced pathogenic mechanisms of $\mathrm{AD}$ in the brain or affected biomarkers of amyloid, tau, or other neuropathology. Comparable doses of simvastatin in hypercholesterolemic subjects without dementia have been found to reduce CSF levels of phosphotau-181 but not total tau, amyloid markers, or isoprostanes. ${ }^{38}$ However, in a small randomized clinical trial in patients with $\mathrm{AD}$, higher doses (80 mg daily) for 26 weeks did not significantly alter CSF levels of $A \beta 40$ and $A \beta 42$, although in a post hoc analysis, of a subgroup with mild $\mathrm{AD}$, simvastatin significantly decreased $A \beta 40$ levels compared to placebo. ${ }^{8}$

A large body of evidence from randomized clinical trials using statins consistently reports no benefit in cognition ${ }^{32,33}$ or dementia prevention, ${ }^{32}$ calling into question the relevance of preclinical and epidemiologic findings.

These results do not support the use of simvastatin for the treatment of AD. Further exploration of 
cholesterol-lowering therapy for treatment or prevention of $\mathrm{AD}$ should be weighed against other treatment approaches with plausible rationales.

\section{AUTHOR CONTRIBUTIONS}

Dr. Sano: drafting/revising the manuscript, study concept or design, analysis or interpretation of data. Dr. Bell: drafting/revising the manuscript, study concept or design, acquisition of data, study supervision. Dr. Galasko: drafting/revising the manuscript, study concept or design. Dr. Galvin: drafting/revising the manuscript, analysis or interpretation of data, acquisition of data. Dr. Thomas: drafting/revising the manuscript, study concept or design, analysis or interpretation of data, statistical analysis, study supervision. Dr. van Dyck: drafting/revising the manuscript, acquisition of data. Dr. Aisen: drafting/revising the manuscript, study concept or design, analysis or interpretation of data, acquisition of data, study supervision.

\section{STUDY FUNDING}

This work was supported by NIA grant U01AG10483. The ADCS received an unrestricted educational grant from Merck who also supplied drug and placebo. Merck did not participate in the design and conduct of the study; collection, management, analysis, and interpretation of the data; or preparation of the manuscript. Authors had full access to all data in the study and take responsibility for the integrity of the data and the accuracy of the data analysis.

\section{ACKNOWLEDGMENT}

The authors thank the following, who participated in the trial: Oregon Health and Science University, PI Jeff Kaye; University of Southern California, PI Lon Schneider; University of California, San Diego, PI Adam Fleisher; University of Michigan, Ann Arbor, Raymond Scott Turner; Mayo Clinic, Rochester, PI Ron Petersen; University of Washington (SIBCR), PI Murray Raskind; Baylor College of Medicine, PI Rachelle Doody; Columbia University, PI Karen Bell; University of Alabama, Birmingham, PI Ed Zamrini; Mount Sinai School of Medicine, PI Mary Sano; Rush University Medical Center, PI David Bennett; Wien Center for Clinical Research, PI Raj Duara; Washington University, St. Louis, PI James Galvin; New York University Medical Center, PI Steve Ferris; Duke University Medical Center, PI Murali Doraiswamy; University of Pennsylvania, PI Chris Clark; University of Kentucky, PI Greg Jicha; University of Pittsburgh, PI Steve DeKosky; University of Rochester Medical Center, PI Pierre Tariot; University of California, Irvine, PI Carl Cotman; University of Texas, Southwestern MC, PI Ramon Diaz-Arrastia; Emory University, PI Allan Levey; University of California, Los Angeles, PI Jeff Cummings; Mayo Clinic, Jacksonville, PI Neil Graff-Radford; Indiana University, PI Martin Farlow; Memorial Hospital Rhode Island, Brown University, PI Brian Ott; Yale University, PI Chris Van Dyck; University of California, Davis, PI Charles DeCarli; SUNY Stony Brook, PI Mark Sedler; Arizona Health Sciences Center, PI Geoffrey Ahern; The Memory Clinic at Southwestern Vermont Medical Center, PI Paul Soloman; Barrow Neurology; PI Jiong Shi; Northwestern University, PI Marek-Marsel Mesulam; Medical University of South Carolina, PI Jocobo Mintzer; Premiere Research Institute, PI Carl Sadowsky; Georgetown University, PI Paul Aisen; Brigham and Women's Hospital, PI Reisa Sperling; Boston University, PI Robert Green; Howard University, PI Thomas Obisesan; Case Western Reserve University, PI Alex Auchus; Neurological Care of CNY, PI Smita Kittur; MD Clinical, PI Kerri Wilks; Stanford, PI Jerome Yesavage; SUNY Downstate, PI Howard Crystal.

\section{DISCLOSURE}

Dr. Sano serves on a scientific advisory board for Medivation, Inc.; serves as a consultant for Bayer Schering Pharma, Bristol-Meyers Squibb, Elan Corporation, Genentech, Inc., Medivation, Inc., Medpace Inc., Pfizer Inc, Janssen, Takeda Pharmaceutical Company Limited, and United Biosource Corporation; and receives research support from the NIH (NIA/ NCRR). Dr. Bell serves on speakers' bureaus for and has received speaker honoraria from Eisai Inc. and Forest Laboratories, Inc.; and receives research support from Baxter International Inc., Wyeth, Pfizer Inc, Janssen Alzheimer Immunotherapy Research \& Development, LLC, and the
NIH/NIA. Dr. Galasko serves on a scientific advisory board for Janssen/ Elan Corporation; serves as Co-Editor for Alzheimer's Research and Therapy; serves as a consultant for United BioSource Corporation; and receives research support from Eli Lilly and Company, Avid Radiopharmaceuticals, Inc., and the NIH/NIA. Dr. Galvin serves on a scientific advisory board for the American Federation for Aging Research and on the Board of Directors and the Scientific Advisory Council for the Lewy Body Dementia Association; serves on the editorial boards of Alzheimer's Disease and Associated Disorders and Acta Neuropathologica; serves on speakers' bureaus for Pfizer Inc, Eisai Inc., Novartis, and Forest Laboratories, Inc.; has served as a consultant for Novartis, Forest Laboratories, Inc., Pfizer Inc, Eisai Inc., Janssen, and Medivation, Inc.; has received license fee payments for AD8 dementia screening test (copyrighted): license agreements between Washington University and Pfizer Inc, Eisai Inc., and Novartis; and receives research support from Novartis, Eli Lilly and Company, Elan Corporation, Wyeth, Bristol-Myers Squibb, the NIH/NIA, and the Alzheimer Association. Dr. Thomas has served on a scientific advisory board for Myriad Genetics, Inc.; has served as a consultant for Medivation, Inc., Myriad Genetics, Inc., Bristol-Meyers Squibb, and Neurochem Inc.; and receives research support from the US Department of Defense and the NIH/NIA. Dr. van Dyck has served on scientific advisory boards for Elan Corporation, Pfizer Inc, GlaxoSmithKline, Bristol-Myers Squibb, and Forest Laboratories, Inc.; has received funding for travel and speaker honoraria from Forest Laboratories, Inc.; his spouse owns or has applied for patents re: Use of guanfacine in the treatment of behavioral disorders, Use of lofexidine in the treatment of behavioral disorders, Chelerythrine, analogs thereof and their use in the treatment of bipolar disorder and other cognitive disorders (formerly licensed to Marinus Pharmaceuticals, Inc.); his spouse receives publishing royalties for The Neuropharmacology of Stimulant Drugs: Implications for AD/HD (Oxford University Press, 2000); serves as a consultant for Elan Corporation, Pfizer Inc, GlaxoSmithKline, Bristol-Myers Squibb, Forest Laboratories, Inc., and Merck Serono, and his spouse serves as a consultant for Shire plc; served on the speakers' bureau for Forest Laboratories, Inc.; receives/ has received research support from Wyeth, Eli Lilly and Company, Pfizer Inc, Bristol-Myers Squibb, Medivation, Inc., Bayer Schering Pharma, Abbott, Elan Corporation, GlaxoSmithKline, Myriad Genetics, Inc., Neurochem Inc, Sanofi-Synthelabo Research, Janssen, Eisai Inc., Merck Serono, Mitsubishi Tanabe Pharma Corporation, the NIH (NIA, NIMH), Alzheimer's Association, American Health Assistance Foundation, and the National Alliance for Research on Schizophrenia and Affective Disorders (NARSAD); his spouse receives research support from Shire plc, the NIH (NIA, NINDS), the Kavli Neuroscience Institute at Yale, and NARSAD; and his spouse has received license fee payments and receives royalties from Shire plc for a patent re: Use of guanfacine in the treatment of behavioral disorders. Dr. Aisen serves on a scientific advisory board for NeuroPhage and Novartis; serves on the editorial boards of BMC Medicine and Alzheimer's Research \& Therapy; is listed as inventor on a patent re: DHA therapy for apolipoprotein E4 negative Alzheimer's disease (potential royalties assigned in full to UCSD); serves as a consultant to Elan Corporation, Wyeth, Eisai Inc., Schering-Plough Corp., Bristol-Myers Squibb, Eli Lilly and Company, NeuroPhage, Merck \& Co., Roche, Amgen, Genentech, Inc., Abbott, Pfizer Inc, Novartis, Bayer Schering Pharma, Astellas Pharma Inc., Dainippon Sumitomo Pharma, BioMarin Pharmaceutical Inc., Solvay Pharmaceuticals, Inc., Otsuka Pharmaceutical Co., Ltd., Daiichi Sankyo, AstraZeneca, Janssen, and Medivation, Inc.; receives research support from Pfizer Inc, Bayer Schering Pharma, Baxter International Inc., and the NIH/NIA; and has received stock options from Medivation, Inc. and NeuroPhage.

Received November 9, 2010. Accepted in final form April 5, 2011.

\section{REFERENCES}

1. Hartmann T, Kuchenbecker J, Grimm MO. Alzheimer's disease: the lipid connection. J Neurochem 2007;103(suppl 1):159-170.

2. Kivipelto M, Solomon A. Cholesterol as a risk factor for Alzheimer's disease: epidemiological evidence. Acta Neurol Scand Suppl 2006;185:50-57. 
3. Haag MD, Hofman A, Koudstaal PJ, Stricker BH, Breteler MM. Statins are associated with a reduced risk of Alzheimer disease regardless of lipophilicity: The Rotterdam Study. J Neurol Neurosurg Psychiatry 2009;80:13-17.

4. Li G, Higdon R, Kukull WA, et al. Statin therapy and risk of dementia in the elderly: a community-based prospective cohort study. Neurology 2004;63:1624-1628.

5. Arvanitakis Z, Schneider JA, Wilson RS, et al. Statins, incident Alzheimer's disease, change in cognitive function, and neuropathology. Neurology 2008;70:1795-1802.

6. Rea TD, Breitner JC, Psaty BM, et al. Statin use and the risk of incident dementia: the Cardiovascular Health Study. Arch Neurol 2005;62:1047-1051.

7. Sparks DL, Sabbagh MN, Connor DJ, et al. Atorvastatin for the treatment of mild to moderate Alzheimer disease: preliminary results. Arch Neurol 2005;62:753-757.

8. Simons $\mathrm{M}$, Schwärzler F, Lütjohann $\mathrm{D}$, et al. Treatment with simvastatin in normocholesterolemic patients with Alzheimer's disease: a 26-week randomized, placebo-controlled, double-blind trial. Ann Neurol 2002;52:346-350.

9. Corder EH, Saunders AM, Strittmatter WJ, et al. Gene dose of apolipoprotein $\mathrm{E}$ type 4 allele and the risk of Alzheimer's disease in late onset families. Science 1993;261: 921-923.

10. Sparks DL, Scheff SW, Hunsaker JC 3rd, Liu H, Landers $\mathrm{T}$, Gross DR. Induction of Alzheimer-like beta-amyloid immunoreactivity in the brains of rabbits with dietary cholesterol. Exp Neurol 1994;126:88-94.

11. Refolo LM, Malester B, LaFrancois J, et al. Hypercholesterolemia accelerates the Alzheimer's amyloid pathology in a transgenic mouse model. Neurobiol Dis 2000;7:321-331.

12. Fassbender K, Simons M, Bergmann C, et al. Simvastatin strongly reduces levels of Alzheimer's disease beta-amyloid peptides Abeta 42 and Abeta 40 in vitro and in vivo. Proc Natl Acad Sci 2001;8:5856-5861.

13. Boimel M, Grigoriadis N, Lourbopoulos A, et al. Statins reduce the neurofibrillary tangle burden in a mouse model of tauopathy. J Neuropathol Exp Neurol 2009;68:314-25.

14. Duong T, Nikolaeva M, Acton PJ. C-reactive protein-like immunoreactivity in the neurofibrillary tangles of Alzheimer's disease. Brain Res 1997;749:152-156.

15. Ridker PM, Rifai N, Pfeffer MA, Sacks F, Braunwald E. Long-term effects of pravastatin on plasma concentration of C-reactive protein: The Cholesterol and Recurrent Events (CARE) Investigators. Circulation 1999;3:230-235.

16. Strandberg TE, Vanhanen H, Tikkanen MJ. Effect of statins on C-reactive protein in patients with coronary artery disease. Lancet 1999;353:118-119.

17. Karlawish J, Kim SY, Knopman D, van Dyck CH, James $\mathrm{BD}$, Marson D. The views of Alzheimer disease patients and their study partners on proxy consent for clinical trial enrollment. Am J Geriatr Psychiatry 2008;16:240-247.

18. Karlawish J, Kim SY, Knopman D, van Dyck CH, James $\mathrm{BD}$, Marson D. Interpreting the clinical significance of capacity scores for informed consent in Alzheimer disease clinical trials. Am J Geriatr Psychiatry 2008;16:568-574.

19. McKhann G, Drachman D, Folstein M, et al. Clinical diagnosis of Alzheimer's disease: report of the NINCDSADRDA Work Group under the auspices of Department of Health and Human Services Task Force on Alzheimer's Disease. Neurology 1984;34:939-944.

20. Folstein M, Folstein S, McHugh P. The Mini-Mental State Examination. J Psychiatr Res 1975;12:189-198.
21. NIH-NIHBLI. Third Report of the Expert Panel on Detection, Evaluation, and Treatment of High Blood Cholesterol in Adults (ATP III Final Report). Available at: http:// www.nhlbi.nih.gov/guidelines/cholesterol/atp3_rpt.htm. Accessed October 2010.

22. Rosen WG, Mohs RC, Davis KL. A new rating scale for Alzheimer's disease. Am J Psychiatry 1984;141:1356-1364.

23. Schneider LS, Olin JT, Doody R, et al. Validity and reliability of the Alzheimer's Disease Cooperative StudyClinical Global Impression of Change (ADCS-CGIC). Alzheimer Dis Assoc Disord 1997;11(suppl 2):S22-S32.

24. Stern Y, Albert S, Sano M, et al. Assessing dependence in Alzheimer's disease. J Gerontol Med Sci 1994;49:M216M222.

25. Cummings J. The neuropsychiatric inventory: assessing psychopathology in dementia patients. Neurology 1997; 48(suppl 6):S10-S16.

26. Mohs RC, Knopman D, Petersen RC, et al. Development of cognitive instruments for use in clinical trials of antidementia drugs: additions to the Alzheimer's disease assessment scale that broaden its scope. Alzheimer Dis Assoc Disord 1997;11:S13-S21.

27. Logsdon RG, Gibbons LE, McCurry SM, Teri L. Quality of life in Alzheimer's disease: Patient and caregiver reports. J Ment Health Aging 1999;5:21-32.

28. Zhu CW, Torgan R, Scarmeas N, et al. Home health and informal care utilization and costs over time in Alzheimer's disease. Home Health Care Serv Q 2008;27:1-20.

29. Rubin DB. Inference and missing data. Biometrika 1976; 63:581-592.

30. R Development Core Team. R: a language and environment for statistical computing: R Foundation for Statistical Computing, Vienna, Austria. Available at: http:// www.R-project.org. Accessed October 2010.

31. Feldman HH, Doody RS, Kivipelto M, et al. Randomized controlled trial of atorvastatin in mild to moderate Alzheimer disease: LEADe. Neurology 2010;74:956-964.

32. Heart Protection Study Collaborative Group. MRC/BHF Heart Protection Study of cholesterol lowering with simvastatin in 20,536 high-risk individuals: a randomised placebo-controlled trial. Lancet 2002;360:7-22.

33. Shepherd J, Blauw GJ, Murphy MB, et al. Pravastatin in elderly individuals at risk of vascular disease (PROSPER): a randomised controlled trial. Lancet 2002;360:1623-1630.

34. Cortes F, Portet F, Touchon J, Vellas B. Six and 18-month changes in mild to moderate Alzheimer's patients treated with acetylcholinesterase inhibitors: what can we learn for clinical outcomes of therapeutic trials? J Nutr Health Aging 2007;11:330-337.

35. Aisen PS, Schneider LS, Sano M, et al. Alzheimer Disease Cooperative Study: high-dose B vitamin supplementation and cognitive decline in Alzheimer disease: a randomized controlled trial. JAMA 2008;300:1774-1783.

36. Green RC, Schneider LS, Amato DA, et al, Tarenflurbil Phase 3 Study Group. Effect of tarenflurbil on cognitive decline and activities of daily living in patients with mild Alzheimer disease: a randomized controlled trial. JAMA 2009;302:2557-2564.

37. Winblad B, Jelic V, Kershaw P, Amatniek J. Effects of statins on cognitive function in patients with Alzheimer's disease in galantamine clinical trials. Drugs Aging 2007;24:57-61.

38. Riekse RG, Li G, Petrie EC, et al. Effect of statins on Alzheimer's disease biomarkers in cerebrospinal fluid. J Alzheimers Dis 2006;10:399-406. 